\title{
The Influence on the Aging Patients with Cholecystitis in Terms of Postoperative Cognitive Function After Being Treated with Com- bination of Dexmedetomidine Remifentanil Sevoflurane Anesthe- sia Compatibility and Combination of Midazolam Fentanyl Isoflu- rane Anesthesia Compatibility
}

\author{
G. CHEN ${ }^{*}$ XIAOMEI HE AND Y. ZHANG ${ }^{1}$
}

Department of Pharmacy the Affiliated Changzhou No.2 People's Hospital of Nanjing Medical University, Changzhou, Jiangsu 213000, ${ }^{1}$ Department of Anesthesiology, the Affiliated Changzhou No.2 People's Hospital of Nanjing Medical University, Changzhou, Jiangsu 213000, China

Chen et al.: The Influence on the Aging Patients with Cholecystitis In Terms of Postoperative Cognitive Function

This research article was conducted to compare the influence on aging patients with cholecystitis in terms of postoperative cognitive function after being treated with Dexmedetomidine+Remifentanil+Sevoflurane anesthesia compatibility and Midazolam+Fentanyl+Isoflurane anesthesia compatibility. Select 240 cases of aging patients who have undergone laparoscopic downward cholecystectomy under general anesthesia in our hospital from July 2016 to June 2018, then divide them into Group A and B, 120 cases for each group. The Group A has been injected with Dexmedetomidine+Remifentanil+Sevoflurane anesthesia compatibility, while the Group B Midazolam+Fentanyl+Isoflurane anesthesia compatibility. Observe and compare at different times Measures of mean arterial pressure, heart rate and Bispectral Index of patients in the two groups after being anesthetized; and the recovery time of spontaneous breathing, orientation and anesthesia, eye-opening time and extubating time; postoperative MMSE evaluation at different times. The difference concerning Measures of mean arterial pressure, heart rate and Bispectral Index of patients in both groups after being anesthetized is not significant $(p>0.05)$; compared with patients in the group $B$, the postoperative orientation recovery of patients in Group A has shortened from $23.08 \pm 3.32 \mathrm{~min}$ to 17.66 \pm 5.15 min. The difference has statistical significance $(p<0.05)$; MMSE evaluation of patients in Group A scores 24.02 \pm 1.95 and $26.40 \pm 2.06$ for $2 \mathrm{~h}$ and $12 \mathrm{~h}$ after the surgery respectively and an improvement can be seen compared with that of Group B, which scores $20.84 \pm 1.63$ and $22.42 \pm 1.95$ respectively. The difference has statistical significance $(\mathbf{p}<\mathbf{0 . 0 5})$. For those aging patients with cholecystitis who have undergone laproscope, the recovery of cognitive function treated with Dexmedetomidine+Remifentanil+Sevoflurane anesthesia compatibility is better than Midozolam+Fentanyl+Isoflurane anesthesia compatibility.

Key words: General anesthesia, postoperative cognitive dysfunction, cholecystitis, Dexmedetomidine, airway extubating, laparoscopes.

With the rapid development of medical technology and the deepening process of population aging, aging patients have increasingly more demands for surgical operations. Due to their aging body and poor function in cardiovascular compensation, aging patients will produce strong stress response to medication, especially under general anesthesia and the anesthesia adopted will do harm to them in terms of hemodynamics and cardiac function, resulting in perioperative period complications $^{[1,2]}$. Anesthesia is highly dangerous for aging patients with potential risks ${ }^{[3,4]}$. Postoperative Cognitive Dysfunction (POCD) is one of the complications in aging patients' central nervous system after being anesthetized, the symptoms are disorder and dysfunction in regard to memory, orientation, cognitive ability and sleeping, which are reversible acute mental disorder syndrome ${ }^{[5,6]}$. And it is related to postoperative recovery delay, medical resource waste and the increase

*Address for correspondence

E-mail: ckg8sp@163.com 
of postoperative complications ${ }^{[7]}$. Therefore, it is of vital importance to find out an anesthetic compatibility method that exerts the least influence on the postoperative cognitive function of aging patients, so as to ensure safe and effective clinical anesthesia and success of the surgery ${ }^{[8,9]}$. In the research, two types of common anesthesia compatibility methods are observed and analyzed, namely Dexmedetomidine+Remifentanil+Sevoflurane anesthesia compatibility and Midazolam+Fentanyl+Isoflurane anesthesia compatibility and their influence on aging patients with POCD. Besides, the depth of anesthesia has also been evaluated. The report is as follows. Select 240 cases of aging patients as the research objects who have undergone laparoscopic downward cholecystectomy under general anesthesia in our hospital from July 2016 to June 2018, among them 107 male cases and 133 female cases with an average age of $67.94 \pm 7.63$. The American Society of Anesthesiologists (ASA) classifies levels from I to II. MMSE is adopted to evaluate the cognitive function of aging patients before the surgery, all of whom are excluded cognitive dysfunction (MMSE scores greater than 27). Exclusion standard: organic lesion in central nervous system; anti-depression and sedative medication has been taken a month before the research; those with systemic diseases like high blood pressure and diabetes; those with dysfunction in important organs like heart, liver, kidney, etc. Cases are divided into group A and B by Random Number Table method, 120 cases for each group; both the groups adopt different anesthesia compatibility methods. 48 male cases and 72 female cases with an average age of $66.38 \pm 5.84$ in group A; 58 male cases and 62 female cases with an average age of $66.11 \pm 6.2$ in group B. It has no statistical significance when it comes to sex, average age, preoperative MMSE evaluation and surgical time ( $\mathrm{p}>0.05)$. After entering the surgical room, patients will be monitored about indicators such as Electrocardiogram ECG, oxyhemoglobin saturation, blood pressure and Bispectral Index (BIS) and an intravenous pathway will be opened. Mechanical ventilation is adopted to the patients intubated to the ventilator. The parameters setting is as follows: fraction of inspired oxygen $100 \%$, oxygen flow $2.0 \mathrm{~L} / \mathrm{min}$, inspiratory/expiratory ratio $1: 2$, tidal volume $6 \sim 10 \mathrm{ml} / \mathrm{kg}$, respiratory rate $10 \sim 15$ times/ min. In group A, $0.5 \mu \mathrm{g} / \mathrm{kg}$ Dexmedetomidine is used for anesthesia induction, $1 \mu \mathrm{g} / \mathrm{kg}$ Remifentanil for intravenous injection; $2.0 \% \sim 3.0 \%$ Sevoflurane constant inhalation for anesthesia maintenance, 0.05 $\sim 0.20 \mu \mathrm{g} / \mathrm{kg} / \mathrm{min}$ ) Remifentanil constant pump-in. In group B, $2 \mathrm{mg}$ Midazolam and $3 \mu \mathrm{g} / \mathrm{kg}$ Fentanyl for intravenous injection; $1.0 \% \sim 2.0 \%$ Isoflurane constant inhalation and $0.03 \mu \mathrm{g} / \mathrm{kg} / \mathrm{min}$ ) Fentanyl constant pump-in for anesthesia maintenance. BIS of patients in both groups should be maintained from $40 \%$ to $60 \%$. Observation for anesthetic safety and effect: before anesthesia induction $\left(\mathrm{T}_{1}\right)$, during skin incision $\left(\mathrm{T}_{2}\right)$, after skin incision $\left(\mathrm{T}_{3}\right)$ and when surgery terminates $\left(\mathrm{T}_{4}\right)$, indicators such as heart rate (HR), Measures of mean arterial pressure (MAP) and BIS of patients in both the groups should be observed and compared; Anesthesia recovery evaluation: recovery time of spontaneous breathing and orientation, eye-opening time and extubation time should be recorded after the surgery; Postoperative cognitive function evaluation: MMSE should be adopted to evaluate the cognitive condition of patients in both groups before anesthesia, $2 \mathrm{~h}, 12 \mathrm{~h}$ and $24 \mathrm{~h}$ after the surgery respectively. Statistical Package for the Social Sciences (SPSS) 19.0 software is adopted to analyze the statistics, mean number \pm standard deviation $(\mathrm{x} \pm \mathrm{s})$ is for quantity measurement materials and $\mathrm{t}$ for inter-group difference testing; case number and percent (\%) is for counting materials and $\chi^{2}$ for inter-group ratio testing, $\mathrm{p}<0.05$ is of statistical significance. It is found that in $\mathrm{T}_{1}, \mathrm{~T}_{2}, \mathrm{~T}_{3}$ and $\mathrm{T}_{4}$, the difference of HR, MAP, and BIS of patients in both groups has no statistical significance $(\mathrm{p}>0.05$, Table 1) It is found that the recovery time of orientation in group A is much shorter than that of group B (in both groups $\mathrm{p}<0.05$ ); the difference concerning the recovery time of spontaneous breathing, eye-opening time and extubating time for patients in both groups has no statistical significance ( $p>0.05$, Table 2$)$ It is found that $2 \mathrm{~h}$ and $12 \mathrm{~h}$ after the surgery, MMSE of group A scores higher than that of group B. The difference is of statistical significance $(p<0.05$, Table 3$)$. With the population aging in China, aging patients have an everincreasing demand for surgery and anesthesia. As POCD in aging patients has been a clinical hotspot in recent years, proper anesthesia compatibility method can not only guarantee the anesthetic safety and curative effect for patients but also improve the condition for those with POCD. Aging people are vulnerable groups to POCD and the occurrence of POCD affects the recovery of surgical diseases, increase the rate of postoperative complications and treatment expense by protracting hospitalization time, which will all together exert a negative influence on the life quality of patients ${ }^{[10,11]}$. In the research, the anesthesia effect is compared between Dexmedetomidine+Remifentanil+Sevoflurane and Midazolam+Fentanyl+Isoflurane on aging patients. The two types of anesthesia are common for clinical practices. MAP and HR are the reliable indicators to reflect the 
hemodynamic of patients under anesthesia. After being anesthetized, MAP and HR of patients in both groups have no obvious difference, indicating that the two types of anesthesia compatibility methods have almost the same influence on patients' hemodynamics; BIS, as one of the effective indicators to reflect the depth of anesthesia, reflects the condition of the cerebral cortex. It is found that patients adopted with the abovementioned two types of anesthesia compatibility methods have no statistical significance in terms of BIS at different times, which shows almost the same effect. Dexmedetomidine+Remifentanil+Sevoflurane are superior to Midazolam+Fentanyl+Isoflurane in regard to orientation recovery and cognitive dysfunction recovery in the early period of post operation. Dexmedetomidine is a new type and highly effective $\alpha 2$ epinephrine receptor stimulant, which owns a high selectivity for the $\alpha 2$ receptor. It inhibits the release of presynaptic membrane norepinephrine to inhibit sympathetic nerve activity, thus producing analgesic and sedative effect. It also slightly inhibits respiration so that the dose of other anesthetics can be reduced ${ }^{[12]}$. When compatible with anesthetics like Remifentanil and Propofol, Dexmedetomidine serves to reduce the total dose of the above mentioned anesthetics so as to lower the risk of other anesthetics in inducing POCD ${ }^{[13]}$. It is showed in the clinical research that if Dexmedetomidine is adopted in heart surgery, the incident rate of postoperative amnesia will be lowered remarkably from $50 \%$ to about $8 \%^{[14]}$. Similar to Fentanyl, Remifentanil is also opioid, but the two are different from each other in the respect of metabolic pathways and pharmacological activity ${ }^{[13]}$. Remifentanil shortens the time of metabolism in aging patients owing to its features, thus lowering the interference to cognitive ability to the minimum. It is also showed in the clinical research that those adopted with Fentanyl and Remifentanil recover faster than those with Fentanyl in terms of cognitive function ${ }^{[15]}$. Due to the decreasing function of important organs like liver and kidney for aging patients, Remifentanil, thanks to its rapid metabolic features free from the influence of liver and kidney, enjoys an advantage for the recovery of postoperative cognitive function to aging patients. Sevoflurane and Isoflurane are medication of the same kind with a similar mechanism of action ${ }^{[16]}$. Compared with Isoflurane, Sevoflurane can increase local cerebral blood flow, improve cerebral blood flow speed, adjust intracranial pressure, lower the sensitivity of the brain to carbon dioxide and act as protection for cerebral ischemia-reperfusion injury, so as to promote the postoperative recovery of functional nerve cells. Under the circumstance where the depth and recovery of anesthesia are more or less the same, Sevoflurane can better protect the cognitive function of aging patients under general anesthesia than Isoflurane in the early period of post operation. Above all, among those aging patients who have undergone laparoscopic treatment, when it comes to the recovery of post operative cognitive function, Dexmedetomidine+Remifentanil + Sevoflurane anesthesia compatibility, which is trustworthy to be popularized for clinical practices, yields better anesthetic effect than Midazolam+Fentanyl+Isoflurane anesthesia compatibility.

\section{Conflict of interests:}

The authors declared no conflicts of interest.

TABLE 1: HR, MAP AND BIS CONDITION OF AGING PATIENTS WITH CHOLECYSTITIS TREATED WITH TWO TYPES OF ANESTHESIA COMPATIBILITY METHODS RESPECTIVELY $(n=120)$

\begin{tabular}{lcccccccccccc}
\hline Group & \multicolumn{3}{c}{ HR (times/min) } & \multicolumn{1}{c}{ MAP (mmg) } \\
\hline \multirow{2}{*}{ Group A } & $\mathrm{T}_{1}$ & $\mathrm{~T}_{2}$ & $\mathrm{~T}_{3}$ & $\mathrm{~T} 4$ & $\mathrm{~T}_{1}$ & $\mathrm{~T}_{2}$ & $\mathrm{~T}_{3}$ & $\mathrm{~T}_{4}$ & $\mathrm{~T}_{1}$ & $\mathrm{~T}_{2}$ & $\mathrm{~T}_{3}$ & $\mathrm{~T}_{4}$ \\
& 32 & 32 & 32 & 32 & 32 & 32 & 32 & 32 & 32 & 32 & 32 & 32 \\
& $73.31 \pm$ & $61.21 \pm$ & $78.50 \pm$ & $88.12 \pm$ & $106 \pm$ & $77.43 \pm$ & $113.11 \pm$ & $98.16 \pm$ & $93.61 \pm$ & $53.72 \pm$ & $59.58 \pm$ & $87.58 \pm$ \\
& 6.19 & 5.01 & 6.61 & 2.50 & 9.60 & 12.3 & 12.4 & 7.5 & 1.4 & 6.9 & 4.8 & 10 \\
Group B & $74.26 \pm$ & $59.63 \pm$ & $76.49 \pm$ & $86.69 \pm$ & $107.14 \pm$ & $75.75 \pm$ & $109.36 \pm$ & $100.03 \pm$ & $94.30 \pm$ & $55.59 \pm$ & $57.16 \pm$ & $89.25 \pm$ \\
& 8.25 & 5.89 & 5.65 & 4.77 & 7.88 & 9.2 & 9.1 & 6.4 & 1.3 & 5.1 & 5.9 & 9 \\
\hline
\end{tabular}


TABLE 2: ANESTHESIA RECOVERY CONDITION FOR AGING PATIENTS WITH CHOLECYSTITIS TREATED WITH TWO TYPES OF ANESTHESIA COMPATIBILITY METHODS RESPECTIVELY ( $x \pm s)$ MIN

\begin{tabular}{lcccc}
\hline Group & $\begin{array}{c}\text { Recovery time of } \\
\text { spontaneous breathing }\end{array}$ & $\begin{array}{c}\text { Recovery time of } \\
\text { orientation }\end{array}$ & Eye-opening time & Extubating time \\
\hline Group A $(\mathrm{n}=120)$ & $15.21 \pm 2.40$ & $17.66 \pm 5.15^{*}$ & $14.26 \pm 3.06$ & $27.19 \pm 2.06$ \\
Group B $(\mathrm{n}=120)$ & $14.96 \pm 3.11$ & $23.08 \pm 3.32$ & $15.29 \pm 3.56$ & $21.31 \pm 1.88$ \\
\hline
\end{tabular}

*Significant differences compared with group $B, p<0.05$.

TABLE 3: THE COMPARISON OF MMSE FOR AGING PATIENTS WITH CHOLECYSTITIS TREATED WITH TWO TYPES OF ANESTHESIA COMPATIBILITY METHODS BEFORE AND AFTER THE ANESTHESIA ( $x \pm s)$ MIN

\begin{tabular}{lcccc}
\hline Group & $\begin{array}{c}\text { Recovery time of } \\
\text { spontaneous breathing }\end{array}$ & $\begin{array}{c}\text { Recovery time of } \\
\text { orientation }\end{array}$ & Eye-opening time & Extubating time \\
\hline Before anesthesia & 2 h after surgery & 12 h after surgery & 24 h after surgery & $27.19 \pm 2.06$ \\
Group A $(n=120)$ & $28.26 \pm 1.97$ & $24.02 \pm 1.70^{*}$ & $26.40 \pm 2.06^{*}$ & $27.19 \pm 2.06$ \\
Group B $(\mathrm{n}=120)$ & $27.93 \pm 2.13$ & $20.84 \pm 1.63$ & $22.42 \pm 1.95$ & $27.34 \pm 2.11$ \\
\hline
\end{tabular}

*Significant differences compared with group B, $\mathrm{p}<0.05$.

\section{REFERENCES}

1. Newman MF, Kirchner JL, Phillips-Bute B, Gaver V, Grocott $\mathrm{H}$, Jones RH, et al. Longitudinal assessment of neurocognitive function after coronary-artery bypass surgery. N Engl J Med 2001;344(6):395-402.

2. Moller JT, Cluitmans P, Rasmussen LS, Houx P, Rasmussen H, Canet $\mathrm{J}$, et al. Long-term postoperative cognitive dysfunction in the elderly: ISPOCD1 study. Lancet 1998;351:857-61.

3. Strøm C, Rasmussen LS, Sieber FE. Should general anaesthesia be avoided in the elderly?. Anaesthesia 2014;69:35-44.

4. Kanonidou Z, Karystianou G. Anesthesia for the elderly. Hippokratia 2007;11(4):175.

5. Rasmussen LS, Larsen K, Houx P, Skovgaard LT, Hanning CD, Moller JT, ISPOCD group. The assessment of postoperative cognitive function. Acta Anaesthesiol Scand 2001;45(3):27589.

6. Jones MJ, Piggott SE, Vaughan RS, Bayer AJ, Newcombe RG, Twining TC, et al. Cognitive and functional competence after anaesthesia in patients aged over 60: controlled trial of general and regional anaesthesia for elective hip or knee replacement. Br Med J 1990;300(6741):1683-7.

7. Misal US, Joshi SA, Shaikh MM. Delayed recovery from anesthesia: A postgraduate educational review. Anesth Essays Res 2016;10(2):164-72.

8. Siikanen J, Sjövall J, Forslid A, Brun E, Bjurberg M, Wennerberg $\mathrm{J}$, et al. An anesthetic method compatible with 18F-FDG-PET studies in mice. Am J Nucl Med Mol Imaging 2015;5(3):270-7.

9. HUTTON JH. Anesthetic Methods Compatible with the Use of Cautery in Thoracic Surgery: A Preliminary Report. Dis Chest 1941;7(12):406-8.

10. Rodgers A, Walker N, Schug S, McKee A, Kehlet H, Van Zundert A, et al. Reduction of postoperative mortality and morbidity with epidural or spinal anaesthesia: results from overview of randomised trials. BMJ 2000;321(7275):1-12.

11. Kotekar N, Kuruvilla CS, Murthy V. Post-operative cognitive dysfunction in the elderly: A prospective clinical study. Indian J Anaesthesia 2014;58(3):263-8.

12. Menda F, Koner O, Sayin M, Ture H, Imer P, Aykac B. Dexmedetomidine as an adjunct to anesthetic induction to attenuate hemodynamic response to endotracheal intubation in patients undergoing fast-track CABG. Ann Card Anaesth 2010;13(1):16-21.

13. Zhang GH, Li S. Peri-intubation hemodynamic changes during low dose fentanyl, remifentanil and sufentanil combined with etomidate for anesthetic induction. Chin Med J 2009;122(19):2330-4.

14. Lawrence CJ, De Lange S. Effects of a single pre-operative dexmedetomidine dose on isoflurane requirements and peri-operative haemodynamic stability. Anaesthesia 1997;52(8):736-45.

15. Glass PS, Hardman D, Kamiyama Y, Quill TJ, Marton $\mathrm{G}$, Donn $\mathrm{KH}$, et al. Preliminary pharmacokinetics and pharmacodynamics of an ultra-short-acting opioid: remifentanil (GI87084B). Anesth Analg 1993;77(5):1031-40.

16. Lee JR, Jung CW, Lee JH, Choi IY, Seo KS, Kim HK, et al. Optimal Dose of Remifentanil to Suppress Cardiovascular Responses to Laryngoscopic Endotracheal Intubation. Korean J Anesthesiol 2005;49(6):780-5.

This is an open access article distributed under the terms of the Creative Commons Attribution-NonCommercial-ShareAlike 3.0 License, which allows others to remix, tweak, and build upon the work non-commercially, as long as the author is credited and the new creations are licensed under the identical terms

This article was originally published in a special issue,
"Trends in Therapeutic Management of Various Clinical
Conditions II" Indian J Pharm Sci 2021:83(2)Spl issue;171-174

